\title{
InSAR tools for risk assessment over mine assets
}

\author{
JL Morgan TRE Altamira, Australia \\ D Colombo TRE Altamira, Italy \\ F Meloni TRE Altamira, Italy
}

\begin{abstract}
Ground motion over mine sites, while an everyday occurrence, may represent hazards that need to be identified and monitored over time. An accurate and regularly updated overview of surface movement over mining operations is therefore critical as part of an ongoing risk assessment program. By having a complete picture of ground stability, movement patterns which represent potential geotechnical hazards to safety and mine operations can be identified and tracked over time. From routine monitoring to high-frequency updates, interferometric synthetic aperture radar (InSAR) technology is increasingly being used to identify a wide range of movement patterns which may be of concern to mine operators and geotechnical engineers.

Recent advances in radar image processing algorithms, combined with an increase in the number of satellite systems launched into orbit, have resulted in improvements in the ability of this technology to capture complex and rapid displacement. In particular, the ability to characterise rapid and sudden motion (metres of movement) has increased the utility of InSAR from a practical standpoint in characterising geotechnical hazards. Further exploitation of 2D monitoring approaches in capturing vertical and horizontal movement, particularly for producing displacement vectors along cross sections, can also provide additional insights into hazard characterisation. Key differences between the ability of high-resolution imagery to capture complex and rapid deformation in comparison to low-resolution (but freely available) Sentinel imagery are also touched upon.

This paper will focus on the practical application of InSAR technology to monitor mine sites around the world, illustrating how new processing approaches and data sources are used in the identification of geomechanical risks that are typically of greatest concern from both an operational and safety standpoint. Examples of results over an active mine site will be shared and a particular emphasis will be placed on selecting the right InSAR tool for helping geotechnical engineers best manage risk due to movement.
\end{abstract}

Keywords: open pit, InSAR, slope stability, tailings dam, hazard mapping, displacement monitoring, radar imagery, SAR, deformation maps, surface profiles, displacement vectors

\section{Introduction}

Mining, by its very nature, involves the displacement of rocks to create open pits, underground voids, dumps and tailings storage areas, all of which are subject to instability. These instabilities may pose risks to the safety of mine workers as well as ongoing operations and production of the mine itself. It is therefore critical to implement a monitoring strategy capable of identifying and tracking these movements over time. A wide range of technologies are being used to assess the stability of mine sites on an ongoing basis. Remote monitoring systems, such as interferometric synthetic aperture radar (InSAR), are increasingly being utilised for displacement monitoring, particularly in order to provide a site-wide overview of displacements which cannot be as effectively captured using ground-based systems (Colombo \& MacDonald 2015).

InSAR is the use of radar satellite imagery to monitor ground displacement over time by identifying changes in the returned phase value of the reflected signal. In most cases, measurements can be obtained from features already on the ground, meaning there is no requirement for the installation of any equipment, or access to the site with survey crews. Information on surface motion can also be obtained over large areas, providing a 
site-wide overview of displacement (where measurement points can be identified). In most cases, this means a superior density and spatial extent of data coverage in comparison to ground-based monitoring systems.

Just as InSAR provides considerable advantages for deformation monitoring, it is important to note the limitations of the technology. For instance, measurements cannot be obtained over areas that are not visible to the satellite (portions of open pits or other steep slopes can be problematic) and from areas where the reflected signal decorrelates over time (dense vegetation, excavation/dumping or water). Furthermore, new data can only be collected once every $8,11,12,14$ or 24 days depending on the satellite system being exploited. Therefore, the successful use of InSAR for safety and operational critical monitoring is dependent upon two factors:

1. The selection of a radar system and processing/reporting frequency that meets the monitoring needs of the mine site and matches the characteristics of any displacement hazards.

2. The integration of InSAR data with real-time, ground-based technologies for effective risk management.

This paper aims to present an overview of InSAR technology for the monitoring of mine operations within a risk framework. Specifically, the objective will be to discuss the fit of InSAR for hazard identification and monitoring, using examples of results obtained over a mining operation to illustrate the strengths and limitations of the technology. A qualitative discussion on the importance of integration between ground-based and remotely sensed technologies for capturing and characterising motion will also be carried out.

\section{$2 \quad$ InSAR tools and considerations}

There are several factors to take into consideration when designing an InSAR monitoring program over a mine site. These include the input data (type of radar imagery and single versus dual geometry) as well as the type and frequency of updating (rapid delivery maps versus long-term analyses). The following section provides an overview of these factors, as well as how these decisions fit within a risk assessment framework.

\subsection{Radar satellite data}

Radar imagery is collected as a form of active remote sensing in which a microwave signal is transmitted from the satellite and the reflected signal is detected and recorded. Changes in the reflected signals are then analysed and converted into surface displacement over time. The analysis of radar imagery can be divided into either the processing of historical archive data or the use of imagery for ongoing monitoring. The first satellite with a synthetic aperture radar (SAR) sensor on its payload was launched in 1992, meaning historical information may be available over any given site back until 1992 due to this first generation of radar satellites. For the purposes of this paper, a detailed overview of historic radar satellites (i.e. satellites no longer collecting imagery) will not be covered. Rather, the primary focus will be to provide an overview of the radar satellites still currently in operation.

Currently, operational and commercial radar satellites can generally be divided into two main groups; C-band and X-band (Figure 1). C-band imagery is collected with a wavelength that is $5.9 \mathrm{~cm}$ (Sentinel) or $5.6 \mathrm{~cm}$ (Radarsat-2) in length, whereas X-band data is collected using a wavelength that is $3.1 \mathrm{~cm}$ (Cosmo-SkyMed and TerraSAR-X) in length. The wavelength of the radar signal is important since this determines the extent to which deformation can be detected. Typically, movement occurring within the half range of the radar wavelength can be resolved image-to-image (larger amounts lead to phase ambiguity or difficulty in converting phase change to displacement). However, in cases of predictable movement trends (i.e. subsidence bowls), higher amounts of motion can be captured by stitching together displacement over space. A third group of radar satellites exists which collect L-band imagery, which has a wavelength of $22.9 \mathrm{~cm}$ (such as ALOS-2); however, imagery cannot be tasked with this system (the mission is already set). Therefore, this paper primarily focuses on the analysis of systems that can be tasked or provide worldwide coverage (X- and C-band data). 
The other crucial factor in the ability of InSAR to capture and characterise displacement is the pixel size of the radar imagery being analysed. In general, the X-band systems (Cosmo-SkyMed and TerraSAR-X) have a standard pixel size of $3 \times 3 \mathrm{~m}$, with finer resolutions also possible in different acquisition modes (down to $0.25 \times 0.25 \mathrm{~m}$ in Staring Spotlight mode with the TerraSAR-X system). The Radarsat- 2 satellite can also collect data with a resolution of $3 \times 3 \mathrm{~m}$ in multi-look fine mode. In contrast, the Sentinel system captures imagery with a cell resolution of $20 \times 5 \mathrm{~m}$. Pixel size is important because in general, the smaller the pixel size, the higher the density of measurement points that can be identified and the greater amount of detail that can be captured (Figure 2). For instance, the maximum theoretical density of measurement points from a Sentinel analysis is approximately 10,000 points $/ \mathrm{km}^{2}$, in comparison to a theoretical density of $16,000,000$ points $/ \mathrm{km}^{2}$ from a TerraSAR-X staring spotlight analysis.

Satellite

Repeat Time (Days)

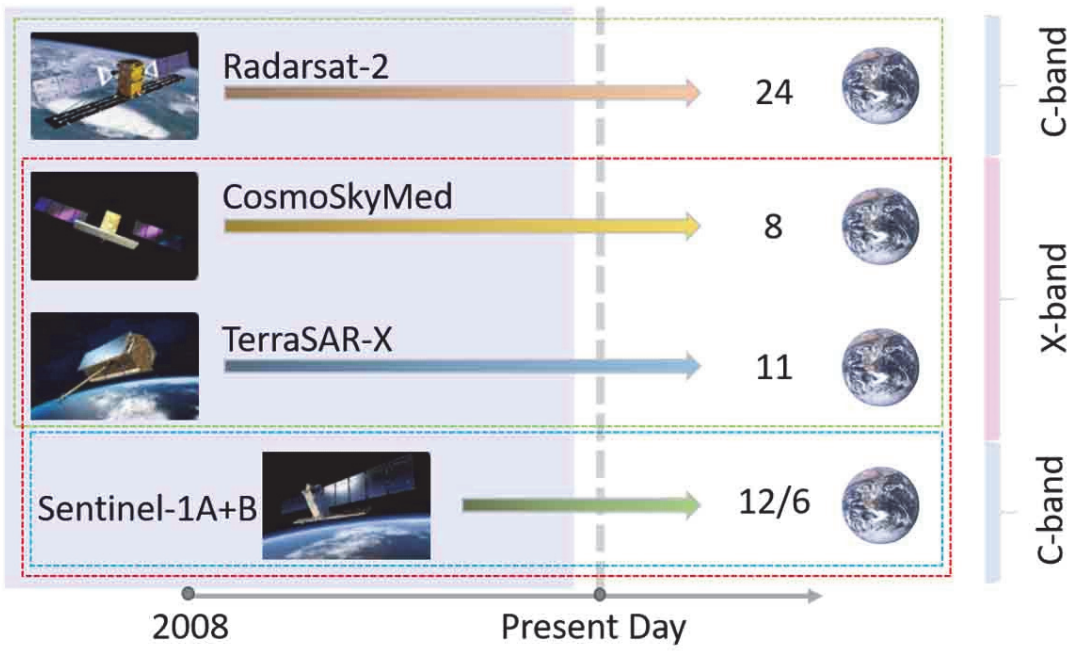

Figure 1 Overview of currently operational C- and X-band radar satellite systems. Satellites outlined with green dashed line indicate satellites that may be programmed (including double geometry options), satellites outlined in red represent satellites with repeat frequency of 12 days or less, while the Sentinel system outlined in blue is acquiring data over all of terrestrial Earth (but cannot be tasked or modified, therefore dual acquisitions are limited to the pre-existing tasking mission)

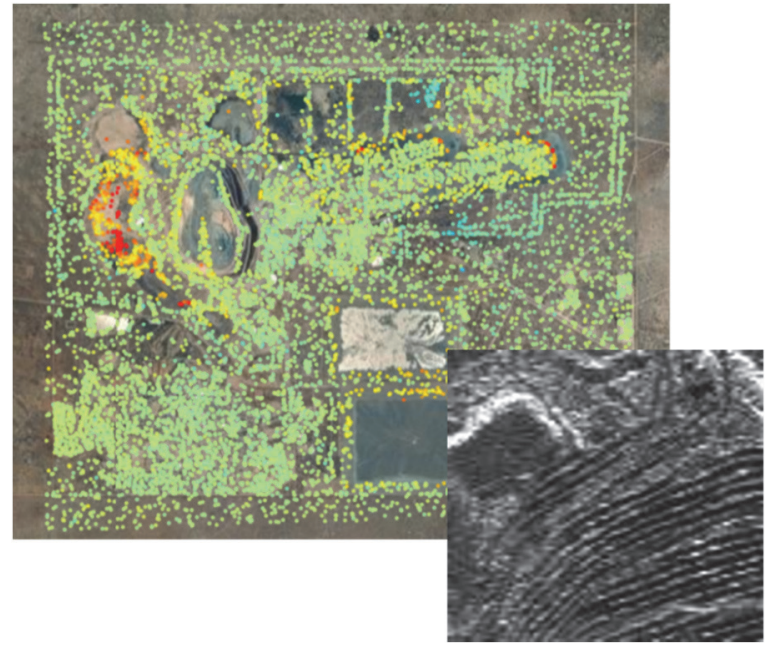

(a)

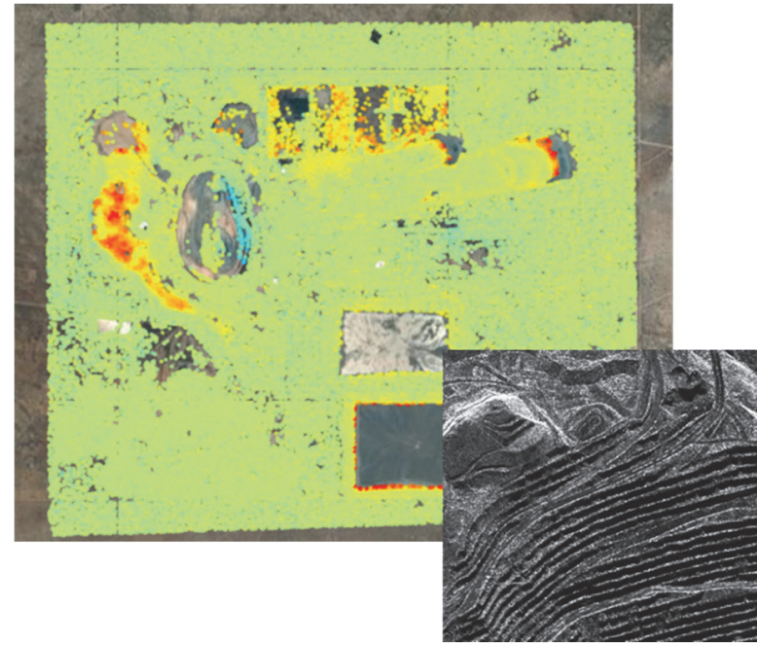

(b)

Figure 2 Contrast in the measurement point density achievable with (a) medium resolution Sentinel C-band imagery versus (b) high-resolution TerraSAR-X imagery. The two inset black and white images represent amplitude images, showing the strength of the reflected radar signal and the resolution of detail possible from these two data sources 
Another important factor regarding pixel size is that the analysis of imagery with smaller pixel sizes allows for additional processing techniques to be applied in order to characterise rapid or sudden movements, which can often fill in gaps and capture motion that may be lost through decorrelation using traditional InSAR approaches. This is particularly important for slope movement within open pits and sudden subsidence over block caving operations. The trade-off is that along with the larger pixel sizes, a larger area can be captured within a single image footprint. Sentinel images are typically more than $50,000 \mathrm{~km}^{2}$ in size, where a Spotlight TerraSAR-X scene is $1,500 \mathrm{~km}^{2}$ in size.

\subsection{Data processing approaches}

With regards to the processing of radar imagery, there are two main approaches that can be exploited for the purposes of initial and ongoing risk assessment. The first approach is the comparison of the returned phase values of two single radar images to capture and identify any changes, also referred to as interferograms (Massonnet et al. 1998). The second approach is the analysis of a stack of radar imagery (minimum of 15 to 20 images) in order to identify features that provide a consistent reflection over time. The reflected values of these identified features are then analysed to characterise displacement over time, from either phase values using multi-interferometric processing algorithms (Ferretti et al. 2001, 2011) or amplitude values using a rapid motion tracking approach (Paradella et al. 2015).

The output of these two types of processing approaches are distinctly different and as such, have different applications when it comes to the monitoring of mine sites, particularly from a risk assessment standpoint.

Interferograms provide a quick snapshot of deformation, highlighting changes occurring over a short period of time (refer to the repeat time of each system shown in Figure 1). These raster maps can be generated quickly, typically within hours of image receipt, and are used for the rapid characterisation of movement trends over a mine site (wherever the ground surface is visible to the satellite and conditions are suitable for InSAR, i.e. not densely vegetated). Within the context of risk assessment, rapid delivery deformation maps are used to identify newly developing hazards and/or track changes in the magnitude of displacement over areas of known deformation. This type of monitoring is typically most often applied to monitor large and/or high-risk mine sites undergoing active operation where regular deformation is expected to occur.

Multi-interferometric and combined multi-interferometric/RMT approaches on the other hand, provide detailed histories of surface movement occurring over longer periods of time (typically multiple years). The output of this type of analysis is a network of measurement points identified from natural features on the surface (wherever a consistent reflection of the radar signal can be identified during the time period covered by the radar data), each of which have their own unique time series of displacement. Within the framework of risk assessment, this type of processing approach is often used for site-wide assessment of geohazards by providing historical context to movement patterns observed over the mine site. This type of information may be particularly valuable for highlighting any changes in displacement rates, particularly acceleration, which may signify the potential onset of more serious events. Furthermore, if events have occurred historically, a back-analysis of displacement conditions prior to failure may even be used to assist with the calibration of geotechnical models.

This type of monitoring can be valuable throughout the entire life cycle of a mine, from site development (to identify naturally occurring displacement hazards such as landslides or tectonic movement), active operations (track long-term displacement patterns and movement behaviours over active mine operations) and site closure (assessment of displacement hazards during decommissioning and to fulfil regulatory requirements for monitoring post-production from environmental and safety standpoint). An overview of the suggested role of InSAR processing approaches within a mining environment is shown in Figure 3 . While the monitoring needs of each mine will vary depending on the unique geologic characteristics of the site and the type of mining (both of which will influence the extent to which deformation hazards will be present), it is important to select the InSAR tools best able to assess risk accordingly and meet those monitoring needs. 


\section{Mine Life Cycle: InSAR Monitoring}

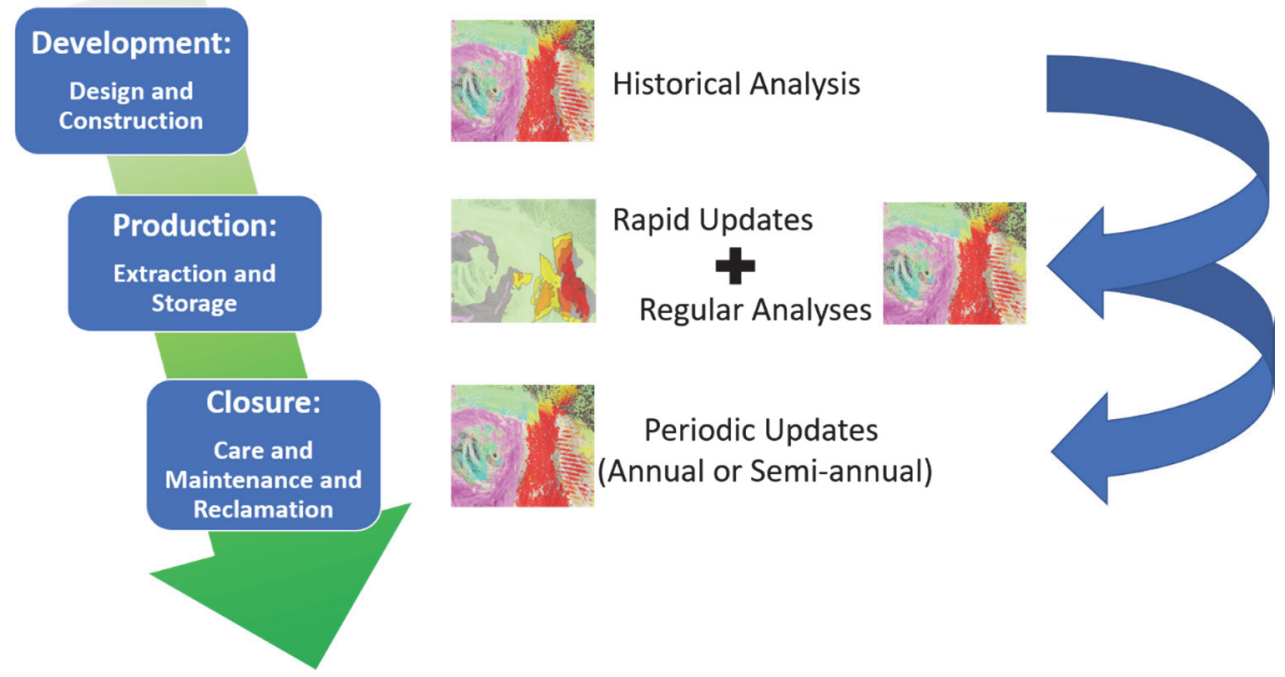

Figure 3 Overview of the suggested role of InSAR tools for the monitoring of mine sites throughout their life cycle

\subsection{Single versus double geometry}

A unique characteristic of radar satellites is that they do not acquire imagery on a nadir, or strictly vertical, look angle. Rather SAR data is collected along a look angle that deviates between $20^{\circ}$ and $50^{\circ}$ from the vertical, known as the line of sight (LOS). This means that movement is captured as occurring either away from the satellite (negative values) or towards the satellite (positive values). Radar satellites are quasi-polar orbiting and continuously collecting imagery as they circle the Earth, capturing data along both ascending orbital passes (satellite travelling from south to north) and descending orbital passes (satellite travelling from north to south).

In most cases, displacement in natural settings contains components of both vertical and horizontal motion, which is also true over mine sites. As a result, all single geometry InSAR data should be interpreted with the satellite LOS angle in mind. This is particularly important when strong horizontal deformation is present, since horizontal motion towards the satellite will be interpreted with positive values. For sites where both geometries have collected data, the two LOS datasets can be combined and decomposed using vector geometry to estimate true vertical and east-west horizontal vectors of movement. The identification of movement in the north-south horizontal direction using this type of InSAR approach is not possible as this direction corresponds to the approximate direction the satellites are orbiting in.

The ability to isolate vertical and horizontal movement trends is particularly beneficial for improved risk assessment over mine operations, since this allows for improved characterisation of displacement hazards. Horizontal motion may present different types of stress for geohazards in both open pit (such as slope instabilities) and underground operations (such as panel closure in longwall mining). By capturing detailed displacement vectors of horizontal movement, the impact of these stresses can be better managed.

Some of the most important factors to consider when designing or updating an InSAR monitoring program are summarised in Table 1. A brief summary of the main advantages and limitations of each factor is also provided. While this table aims to provide a general guide for helping to understand the various InSAR tools available for displacement monitoring, the selection of these tools for ongoing risk assessment and hazard monitoring of a mine will depend upon the characteristics and needs of each site. Similar to any technology, the use of InSAR as part of an ongoing monitoring strategy is most effective when routinely evaluated and updated. 
Table 1 An overview of the advantages and limitations of the selection of input radar data and processing approaches as applied to the monitoring of mine sites

\begin{tabular}{|c|c|c|}
\hline InSAR Monitoring & Advantages & Limitations \\
\hline \multirow{6}{*}{$\begin{array}{l}\text { Medium resolution } \\
\text { input data (Sentinel) }\end{array}$} & Sentinel data freely available (ESA) & \multirow{2}{*}{$\begin{array}{l}\text { Ascending and descending (dual } \\
\text { geometry) not usually available }\end{array}$} \\
\hline & Worldwide coverage with records & \\
\hline & starting in $2014 / 15$ for most areas & \multirow{2}{*}{$\begin{array}{l}\text { Larger pixel size, so challenging to } \\
\text { identify small movement features }\end{array}$} \\
\hline & Some areas (Europe) data are & \\
\hline & acquired every 6 days & \multirow{2}{*}{$\begin{array}{l}\text { Rapid motion tracking cannot typically } \\
\text { be applied }\end{array}$} \\
\hline & Well suited for regional analyses & \\
\hline \multirow[t]{3}{*}{$\begin{array}{l}\text { High-resolution } \\
\text { input data }\end{array}$} & $\begin{array}{l}\text { Ascending and descending orbits can } \\
\text { be tasked (dual geometry) }\end{array}$ & $\begin{array}{l}\text { Historical records rare, especially for } \\
\text { remote areas }\end{array}$ \\
\hline & $\begin{array}{l}\text { Smaller pixel size so smaller areas of } \\
\text { movement can be identified }\end{array}$ & \multirow[t]{2}{*}{ Data has an associated cost } \\
\hline & $\begin{array}{l}\text { Highest density of measurement } \\
\text { points possible }\end{array}$ & \\
\hline \multirow[t]{2}{*}{$\begin{array}{l}\text { 1D or single geometry } \\
\text { input data }\end{array}$} & \multirow[t]{2}{*}{$\begin{array}{l}\text { Data input costs are lower since only } \\
\text { one dataset is acquired }\end{array}$} & $\begin{array}{l}\text { Motion is only captured along the } \\
\text { satellites LOS }\end{array}$ \\
\hline & & $\begin{array}{l}\text { Cannot separate vertical and } \\
\text { horizontal components of motion }\end{array}$ \\
\hline \multirow[t]{4}{*}{$\begin{array}{l}2 \mathrm{D} \text { or dual geometry } \\
\text { input data }\end{array}$} & \multirow{2}{*}{$\begin{array}{l}\text { Opposing data can be combined to } \\
\text { extract vertical and east-west } \\
\text { horizontal components of motion }\end{array}$} & $\begin{array}{l}\text { Higher associated data costs in the } \\
\text { case of high-resolution data }\end{array}$ \\
\hline & & \multirow{2}{*}{$\begin{array}{l}\text { North-south motion cannot be } \\
\text { resolved (satellites polar orbiting) }\end{array}$} \\
\hline & \multirow{2}{*}{$\begin{array}{l}\text { Improved characterisation of } \\
\text { displacement }\end{array}$} & \\
\hline & & $\begin{array}{l}\text { Sentinel imagery not often collected } \\
\text { as dual geometry }\end{array}$ \\
\hline \multirow{3}{*}{$\begin{array}{l}\text { Rapid deformation } \\
\text { maps (interferograms, } \\
\text { DInSAR) }\end{array}$} & $\begin{array}{l}\text { Results can be obtained within hours } \\
\text { of image receipt }\end{array}$ & \multirow[t]{3}{*}{ No time series of deformation } \\
\hline & $\begin{array}{l}\text { Limited decorrelation from mine } \\
\text { works due to short time coverage }\end{array}$ & \\
\hline & Centimetric precision & \\
\hline \multirow[t]{6}{*}{$\begin{array}{l}\text { Multi-interferometric } \\
\text { analyses }\end{array}$} & $\begin{array}{l}\text { Time series capture complex and } \\
\text { non-linear movement histories }\end{array}$ & $\begin{array}{l}\text { Data processing requires days/weeks } \\
\text { to carry out }\end{array}$ \\
\hline & $\begin{array}{l}\text { Results can reach thousands of points } \\
\text { per square kilometer }\end{array}$ & $\begin{array}{l}\text { Decorrelation more widespread due } \\
\text { to longer time span of imagery }\end{array}$ \\
\hline & $\begin{array}{l}\text { Multi-interferometric approaches } \\
\text { have millimetric precision, capture } \\
\text { rates between } 1 \text { to } 1,500 \mathrm{~mm} / \text { year }\end{array}$ & $\begin{array}{l}\text { RMT is typically only applicable to } \\
\text { high-resolution imagery }(3 \times 3 \mathrm{~m} \text { pixel } \\
\text { sizes or less) }\end{array}$ \\
\hline & $\begin{array}{l}\text { Rates between } 1 \text { to } 100 \mathrm{~m} / \text { year } \\
\text { captured with RMT }\end{array}$ & \multirow[t]{3}{*}{$\begin{array}{l}\text { Precision of the RMT approach is } \\
\text { approximately } \pm 20 \mathrm{~cm}\end{array}$} \\
\hline & $\begin{array}{l}\text { 3D displacement vectors can be } \\
\text { identified from RMT results when dual } \\
\text { geometries are processed }\end{array}$ & \\
\hline & $\begin{array}{l}\text { RMT results can be identified in } \\
\text { vegetated areas }\end{array}$ & \\
\hline
\end{tabular}




\subsection{Defining a monitoring approach}

The effective implementation of InSAR for the monitoring of mine sites is dependent upon the selection of a combination of tools that serves to meet the operational needs of the mine. While a broad overview of the role of different processing approaches at different stages of the mining cycle is provided in Figure 3 and an overview of input parameters is provided in Table 1, a more detailed breakdown of how to approach the design of an InSAR monitoring program for mines (including comments on how InSAR tools can contribute towards a risk assessment strategy) can be found in Figure 4. Every mine site is unique and will therefore have slightly different hazards/displacement patterns to monitor, as well as tolerance to risk. However, there are some general guidelines that can be taken into consideration.

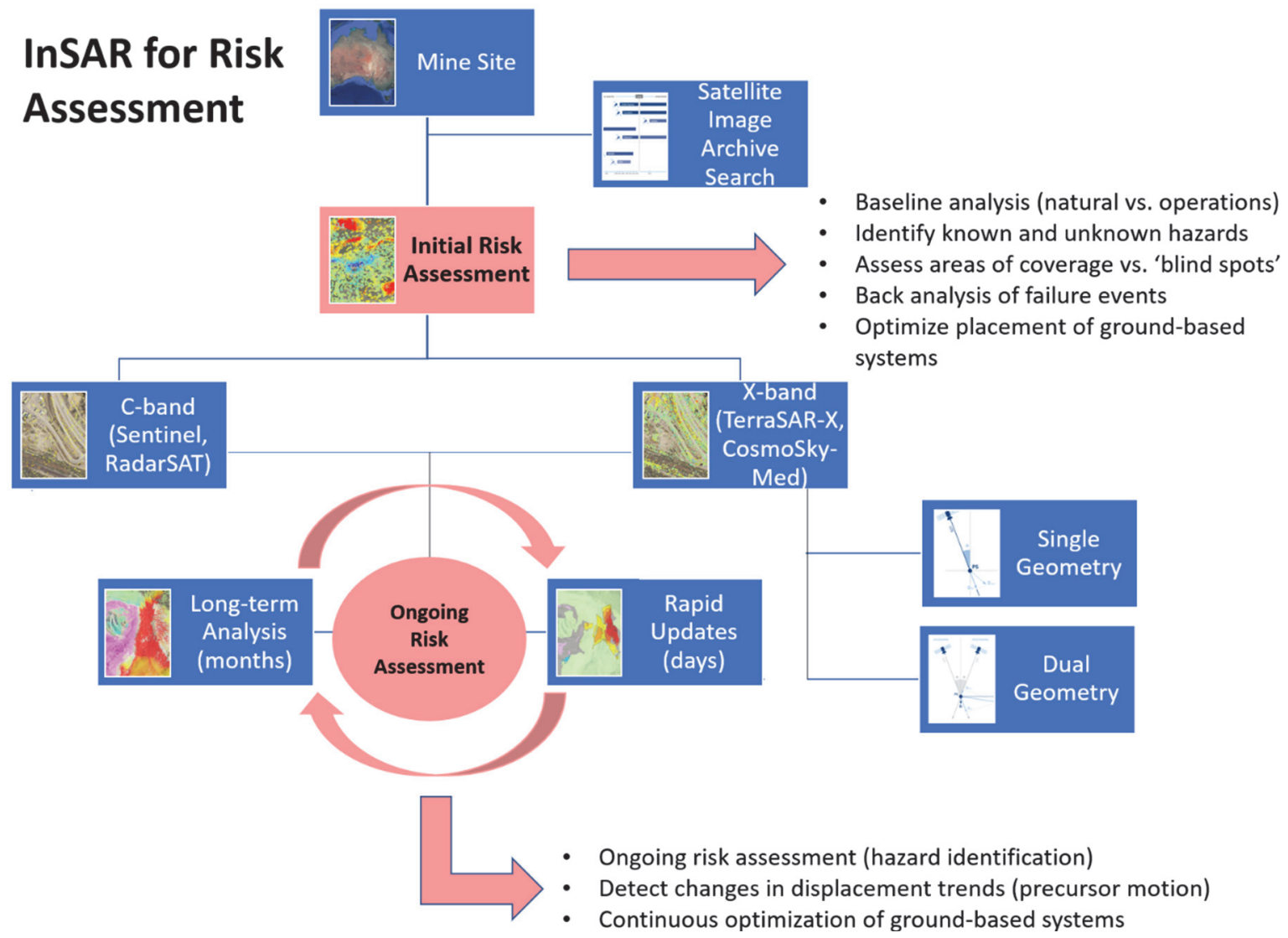

Figure 4 General guidelines for the design of an InSAR monitoring approach over a mine site, illustrating the potential fit of this technology for ongoing risk assessment

InSAR tools range from a one-off multi-interferometric analysis of Sentinel imagery to a dual geometry high-resolution data processing with combined rapid deformation map updates and periodic multi-interferometric/RMT analyses. This diversity is beneficial as it allows for InSAR monitoring to be tailored towards the individual needs of each mine. In general, smaller mines that do not experience a high amount of deformation may be better suited for low frequency monitoring. In contrast, mine facilities where movement is anticipated to be more widespread, complex and/or unpredictable may benefit from more rapid and regular reporting. Similar arguments can be made when deciding upon the input radar imagery. For instance, the higher the potential for rapid deformation or for small movement features to develop, the stronger the case for using high-resolution, dual geometry input data.

As important as the selection of suitable input parameters for InSAR monitoring are, it is almost equally important to understand how this technology can complement existing monitoring techniques. For instance, InSAR data may be able to capture information over areas of a mine site not easily or effectively covered by existing ground-based monitoring approaches. However, real-time monitoring of highest risk areas (such as pit walls and benches) with instruments such as ground-based radar systems can provide safety critical 
information over areas not visible within radar imagery. Ongoing integration between remote systems such as InSAR and ground-based systems will only serve to improve risk assessment going forward by providing a holistic view of stability over mine sites with data reported on temporal scales relevant to operations.

\section{Case study}

The following section presents examples of results obtained over an open pit mine site in order to illustrate the use of different InSAR-based tools for identifying displacement patterns related to different geohazards. A brief discussion of how InSAR is used for ongoing risk assessment over these types of features/assets is also included.

\subsection{Rapid deformation maps}

Deformation maps (derived from interferograms or image pair comparisons) allow for the identification of new hazards within, or adjacent to mine operations, as well as any sudden changes in the conditions of existing hazards (i.e. accelerations). An example of a rapid delivery deformation map over an open pit mining operation is shown in Figure 5. Results highlight the spatial extent of a slope instability developing along the eastern edge of the pit wall (with coverage extending back beyond the crest of the pit itself). Ongoing monitoring of this hazard with deformation maps takes place once every 11 days to verify that the extent and magnitude of motion occurring is not expanding (and therefore becoming higher risk to operations).

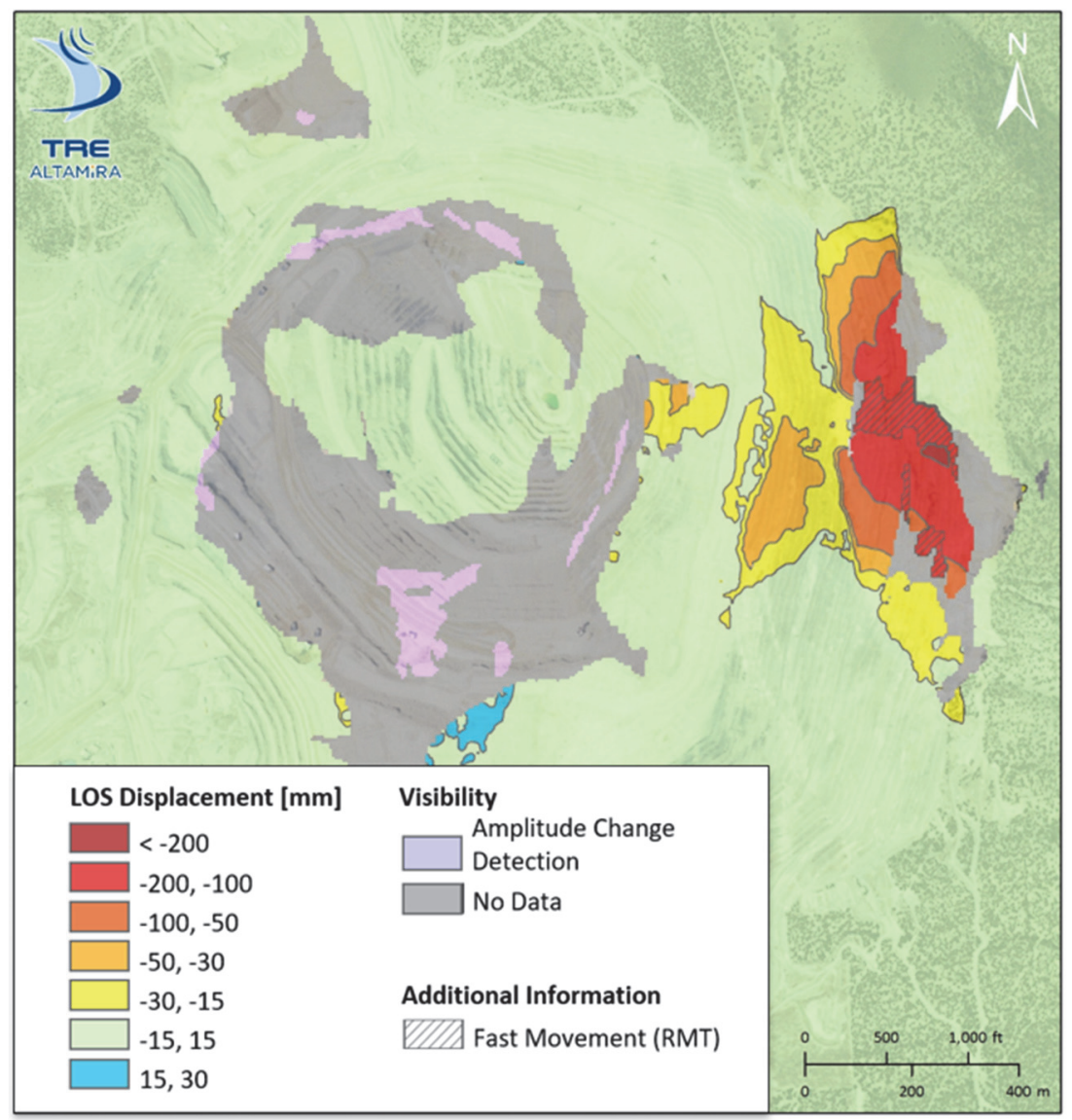

Figure 5 Example of a high-resolution deformation map derived from the analysis of a pair of TerraSAR-X images. The displacement shown was captured over an 11-day period and highlights instability along the eastern side of an open pit, including over the pit crest 
Within a risk assessment framework, this tool can be used to supplement the monitoring of higher risk or safety critical areas which are not (or cannot be) fully covered by ground-based monitoring approaches. These areas may include pit crests, tailings dams and tailings storage facilities, waste piles and dumps, conveyor belts, access road stability and other mine infrastructure, as well as potential hazards within the surrounding terrain that may present a threat to mine operations. Larger mine operations, or mines which have a larger number of potential hazards, may be best suited for monitoring with this type of approach.

\subsection{Multi-interferometric approaches}

Movement occurring over mine sites may be highly variable and complex in both magnitude and trend. Displacement ranging from millimetres to meters can occur regularly over mine operations, just as patterns of motion may be non-linear and exhibit multiple changes in direction and rate over time (acceleration and deceleration). By characterising the long-term history of ground displacement (months or years) over a mine site using multi-interferometric InSAR tools, the associated level of risk can be periodically evaluated for various mine assets as part of a more comprehensive ongoing risk assessment strategy.

Results obtained from the analysis of a stack of radar images over an open pit mine are shown in Figure 6. Results show data coverage over most of the pit crest and upper portions of the pit walls. The large area of instability over the eastern edge of the pit is again highlighted, with both the phase and amplitude values of the radar imagery utilised to provide a picture of displacement (from areas visible to the satellite and/or where the radar signal is reflected). Areas shaded in purple correspond to changes in surface conditions to an extent where the radar signal decorrelates (i.e. excavation, dumping, etc.).

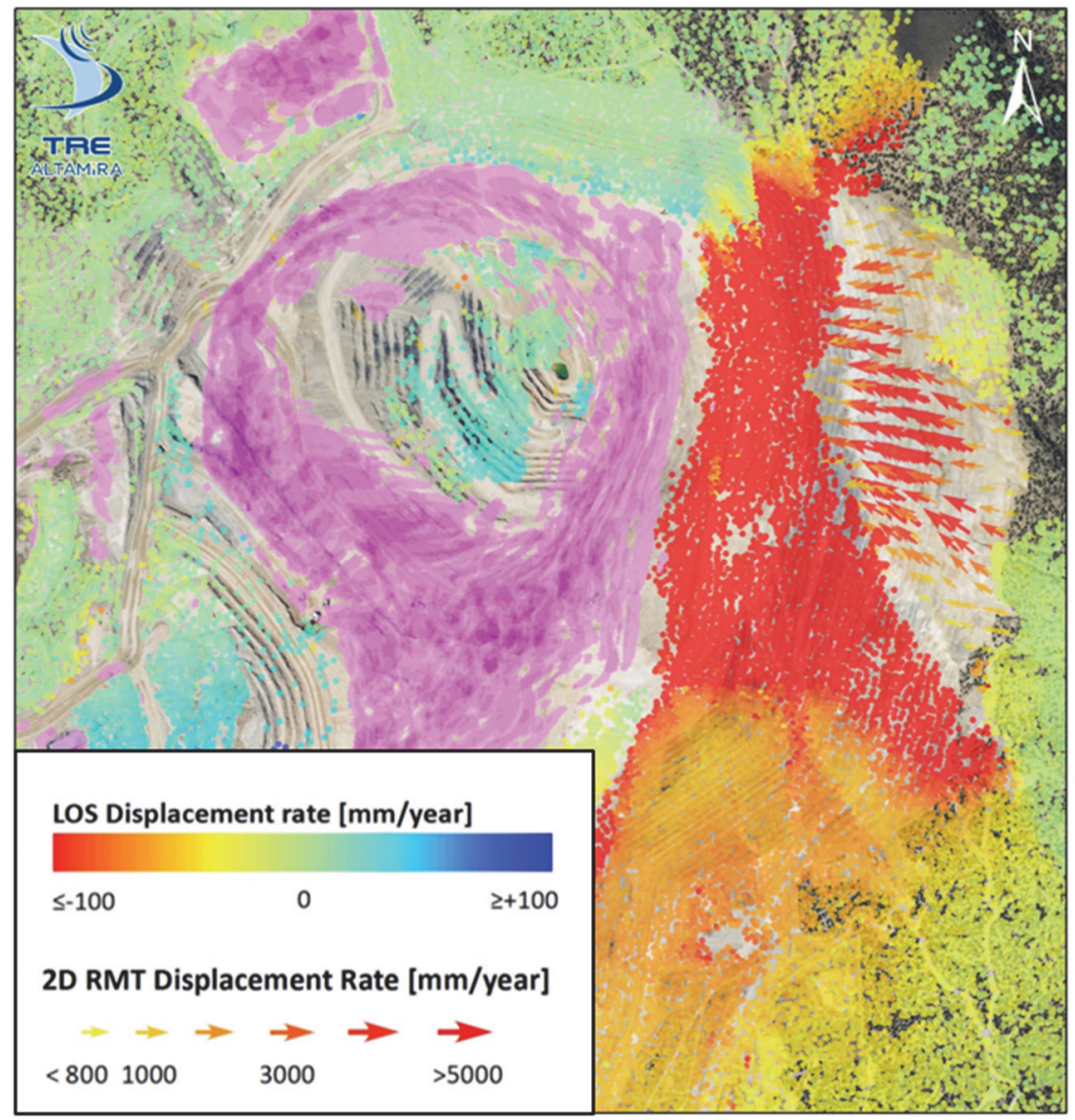

Figure 6 Example of a combined multi-interferometric and RMT analysis produced from a stack of high-resolution TerraSAR-X images covering a time period of six months. The displacement pattern shown highlights the magnitude of deformation over the eastern side of an open pit, including over the pit crest 
As highlighted in Figure 3, this type of InSAR tool may be particularly beneficial for initial risk assessment analyses over undeveloped mine sites to identify potential hazards during mine planning. Over active mines, this type of information may be useful for optimising the placement of ground-based systems to ensure they are covering hazards with the highest potential risk, as well as routinely update displacement histories to capture changes in movement trends. Finally, this type of monitoring strategy can be beneficial for low maintenance monitoring of closed mines or mines that have gone into care and maintenance. Most multi-interferometric/RMT monitoring approaches carried out over mine sites are run on an annual, semi-annual or quarterly basis, and often in parallel with continuous rapid deformation map (DInSAR) monitoring over active mine operations.

\section{$4 \quad$ InSAR data validation and integration}

InSAR measurements have been validated using blind studies with ground-based artificial reflectors (structures specifically designed to reflect the radar signal) to demonstrate the ability of multi-interferometric approaches such as the SqueeSAR algorithm to track displacement over time with sub-millimetric accuracy (Savio et al. 2005; Ferretti et al. 2007). Since then, InSAR measurements have been compared and validated with ground-based instruments including total stations, GPS (Peltier et al. 2010), levelling, and prisms, among others.

Integration of InSAR data onto various monitoring platforms is being increasingly implemented at mine sites to improve risk assessment by helping to verify/confirm, as well as spatially extend the coverage of existing ground-based monitoring. This is particularly so as the spatiotemporal scales at which InSAR can accurately capture and depict displacement trends (short- and long-term trends ranging from weeks to years) is highly complementary to ground-based systems that are real-time and highly precise, yet may not capture and depict long-term trends as accurately. Furthermore, by spatially extending areas of safety critical monitoring covered by real-time instruments, InSAR can improve hazard monitoring and identification over areas that may not be well captured with existing in situ instrumentation.

\section{Conclusion}

Routine assessment of ground displacement over mine operations is important as part of an ongoing risk assessment strategy in order to manage the health of mine assets. InSAR technology offers several tools which can be highly useful for ongoing monitoring of geohazards that pose threats to worker safety or production. The wide-area coverage of radar imagery allows entire mine sites to be captured within a single image including open pits, tailings dams and storage facilities, waste piles and dumps, as well as surrounding areas which may be prone to landslide risk. One of the primary advantages of InSAR tools for assisting in the management of risk is their ability to extend data coverage over safety critical areas (when integrated and coupled with ground-based monitoring technologies), as well as look for new or unknown hazards.

The selection of an InSAR monitoring program and its effective use for monitoring (including the frequency with which these tools are employed over a mine site) is dependent upon the level of risk and extent of geohazards identified at the mine site. In general, the higher the likelihood for high-impact displacement events to occur, the higher the frequency of monitoring updates that are typically recommended. The end objective is to strike a balance between the spatiotemporal resolution of the displacement features occurring at the mine site with an InSAR monitoring program capable of capturing these displacements. When this is successfully achieved and results are integrated with existing ground-based monitoring technologies, a more holistic picture of potential risks to mining operations may be obtained.

\section{Acknowledgement}

The authors thank TRE Altamira for their support during the writing of this paper, especially with the provision of examples used to illustrate the concepts covered in this paper. 


\section{References}

Colombo, D \& MacDonald, B 2015, 'Using advanced InSAR techniques as a remote tool for mine site monitoring', Proceedings of the International Symposium on Slope Stability in Open Pit Mining and Civil Engineering 2015, The Southern African Institute of Mining and Metallurgy, Johannesburg.

Ferretti, A, Prati, C \& Rocca, F 2001, 'Permanent scatterers in SAR interferometry', IEEE Transactions on Geoscience and Remote Sensing, vol. 39, no. 1, pp. 8-20.

Ferretti, A, Fumagalli, A, Novali, F, Prati, C, Rocca, F \& Rucci, A 2011, 'A new algorithm for processing interferometric data-stacks: SqueeSAR', IEEE Transactions on Geoscience and Remote Sensing, vol. 49, no. 9, pp. 3460-3470.

Ferretti, A, Savio, G, Barzaghi, R, Borghi, A, Musazzi, S, Novali, F, Prati, C \& Rocca F 2007, 'Sub-millimeter accuracy of InSAR time series: Experimental validation', IEEE Transactions on Geoscience and Remote Sensing, vol. 45, no. 5, pp. 1142-1153.

Massonnet, D \& Feigl, KL 1998, 'Radar interferometry and its application to changes in the Earth's surface', Reviews of Geophysics, vol. 36, no. 4, pp. 441-500.

Paradella, WR, Ferretti, A, Mura, JC, Colombo, D, Gama, FF, Tamburini, A, Santos, AR, Novali, F, Galo, M, Camargo, PO, Silva, AQ, Silva, GG, Silva, A \& Gomes, LL 2015, 'Mapping surface deformation in open pit iron mines of Carajas Province (Amazon region) using an integrated SAR analysis', Engineering Geology, vol. 193, pp. 61-78.

Peltier, A, Bianchi, M, Kaminski, E, Komorowski, JC, Rucci, A \& Staudacher, T 2010, 'PSInSAR ${ }^{\mathrm{TM}}$ as a new tool to monitor pre-eruptive volcano ground deformation: validation using GPS measurements on Piton', Geophysical Research Letters, vol 37 , issue 12.

Savio, G, Ferretti, A, Novali, F, Musazzi, S, Prati, C \& Rocca, F 2005, 'PSInSAR validation by means of a blind experiment using dihedral reflectors', in W Osten (ed.), The 5th International Workshop on Automatic Processing of Fringe Patterns, Springer, Leipzig. 
